\title{
Respiração circular e sua aplicabilidade ao discurso musical do II movimento da Improvisation et Caprice pour saxophone solo, de Eugène Bozza (1952): proposta interpretativa e análise crítica
}

\author{
Circular breathing and its applicability to the musical \\ discourse of the II movement of Improvisation et Caprice \\ pour saxophone solo, by Eugène Bozza (1952): interpretive \\ proposal and critical analysis
}

(iD) José de Carvalho Oliveira1
josedecarvalhosax@gmail.com

Resumo: No que diz respeito à construção da performance e suas implicações na fidelidade do texto musical, este estudo possui como proposta avaliar a aplicabilidade da respiração circular em comparação à interpretação sem o uso dessa técnica. Sobre as questões conceituais relacionadas à interpretação e à performance, para este trabalho, utilizaremos como referência os estudos de Almeida (2011); em relação à estrutura harmônica, fraseológica e cadencial, a base será o trabalho de Kostka (2015); no que se refere à movimentação horizontal das vozes condutoras, estrutura e prolongação, utilizaremos os estudos de Salzer (1982), e, no tocante à respiração circular, os estudos de Lopes (2018) e Barbosa (2016).

Palavras-chave: Respiração Circular. Saxofone. Interpretação. Performance. Análise Musical. Eugène Bozza.

\footnotetext{
1 Natural de Matias Olímpio, Piauí, José de Carvalho possui mestrado com pesquisa apoiada pela agência de fomento CAPES, sob orientação do Prof. Dr. Paulo de Tarso Salles, na área de Teoria e Análise pela Escola de Comunicação e Artes da Universidade de São Paulo - ECA/USP (2019). É formado em Licenciatura em Música pelo Centro Universitário Sant'Anna - SP e desde 2017 integra o corpo docente na referida instituição. É Professor de saxofone (bacharelado) no Centro Universitário Ítalo Brasileiro - SP. Editor assistente da Revista Música - ECA/USP - SP e, como pesquisador, pertence ao grupo de pesquisa PAMVILLA, Perspectivas Analíticas para a Música de Villa-Lobos. Possui trabalhos publicados no campo da Performance, Teoria, Análise Musical e Educação Musical. Como saxofonista, dedica-se ao repertório brasileiro e contemporâneo. Atua como spalla e maestro assistente na Banda Municipal de Embu das Artes, SP, cidade a qual desenvolve também sólido trabalho como coordenador na Escola Municipal de Música desde sua implantação no ano de 2014.
} 
Abstract: Concerning the construction of performance and its implications in fidelity in the musical text, this study aims to evaluate the applicability of circular breathing compared to interpretation without the use of this technique. On the conceptual issues related to interpretation and performance, for this work, we will use the studies of Almeida (2011) as a reference; relating to the harmonic, phraseological and cadential structure, the basis will be the work of Kostka (2015); with regard to the horizontal movement of the conductive voices, structure and prolongation, we will use the studies by Salzer (1982) and, with regard to circular breathing, the studies by Lopes (2018) and Barbosa (2016).

Keywords: Circular Breathing. Saxophone. Interpretation. Performance. Musical Analysis. Eugène Bozza. 
Respiração circular e sua aplicabilidade ao discurso musical do II movimento... José de Carvalho Oliveira

\section{Introdução}

No que concerne às escolhas interpretativas em relação à preparação para a performance, além de conforto técnico e questões intrínsecas à estética sonora, elementos de comunicação e materialização do enunciado poético são ingredientes essenciais para construção da interpretação e da performance, podendo variar dependendo do gênero, país e/ou cultura (ALMEIDA, 2011, p. 64). Posto isso, o intérprete tende a colocar em primeiro plano a proposta composicional contida no texto musical (partitura), que se estabelece a partir de elementos básicos da notação musical como instrumentação, fórmula de compasso, tonalidade, estilo, andamento, sinais de dinâmica, entre outros elementos imprescindíveis não só para a interpretação como para a performance.

Sob essa perspectiva, da partitura não extraímos apenas informações relacionadas a questões musicais, mas também outros elementos, como dados sobre os sujeitos envolvidos nas práticas musicais - como compositores, intérpretes e ouvintes, além de datas e locais. Partindo desse pressuposto, considerando os efeitos da notação musical enquanto elemento decisivo para o desenvolvimento dos processos interpretativos, as escolhas do intérprete impactam diretamente no resultado da performance.

Da inconsistência de dados para uma completude interpretativa, considerando o enunciado e todas as informações contidas na partitura do segundo movimento da Improvisation et Caprice, de Eugène Bozza (1952), objeto deste estudo, nasce a motivação para uma busca por elementos implícitos e/ou externos à partitura, como, por exemplo, dados contextuais e a utilização de ferramentas de análise musical capazes de interpretar determinados eventos e elementos estruturais da obra.

Considerando essas observações, este estudo propõe uma abordagem interpretativa do ponto de vista conceitual e, também, sob o viés experimental no que se refere à utilização da respiração 
Respiração circular e sua aplicabilidade ao discurso musical do II movimento... José de Carvalho Oliveira

circular como ferramenta de auxílio a um tipo de opção interpretativa. A partir dos estudos de Almeida (2011), em uma análise crítica, confrontamos aspectos interpretativos entre duas perspectivas: a visão de música como processo colaborativo, na interpretação de Dílson Florêncio, e música como forte tradição textual e seu vínculo à partitura enquanto documento fixador, na interpretação do francês Marcel Mule. ${ }^{2}$

Como resultado, este estudo busca oferecer uma reflexão sobre possibilidades alternativas de interpretação, procurando avaliar a aplicabilidade da respiração circular como ferramenta auxiliadora a uma das opções, em comparação à interpretação sem o uso dessa técnica.

\section{EscolhasInterpretativaseaConstruçãodaPerformance}

No tocante ao II movimento denominado Caprice, em relação às escolhas interpretativas com vistas à construção da performance, além dos dados textuais da partitura, utilizamos como base gravações da obra na interpretação do saxofonista francês Marcel Mule (S/D), iii sem o auxílio da respiração circular e, com a utilização da respiração circular, a interpretação do brasileiro, Dílson Florêncio (2009). iv

Em relação às gravações da obra disponibilizadas em plataformas digitais de compartilhamento de vídeos na internet, sobretudo no YouTube, o levantamento feito por esta pesquisa entre os meses de novembro 2019 e agosto de 2020 verificou que a maior

\footnotetext{
i Dílson Afonso Ferreira Florêncio é Professor de saxofone clássico na Universidade Federal da Paraíba - UFPB.

ii Marcel Mule, segundo professor de saxofone no Conservatório Superior de Música de Paris, sucessor de Adolphe Sax (18141894), o criador do instrumento. Mule foi um dos responsáveis pelo desenvolvimento do instrumento, bem como de seu repertório, já que renomados compositores dedicaram obras a ele.

iii Disponível em: https://www.youtube.com/watch?v=Mpx2eO004lı. Acesso em: 14 dez. 2019.

iv Disponível em: https://www.youtube.com/watch?v=C4clEdsqty4. Acesso em: 14 dez. 2019.

v Rafael Mendez, Flight of the Bumblebee, Mexican Hat Dance (S/D). Disponível em: https://www.youtube.com/watch?v=zPbfj3WxRA. Acesso em: 27 dez. 2019.

vi Paulo Moura. Moto Perpetuo de Paganini, programa Hebe Camargo (TV aberta) (S/d.). Disponível em:

https://www.youtube.com/watch?v=r75koRj3gkg\&t=1s. Acesso em: 27 dez. 2019.

vii Este estudo foi iniciado no ano de 2013 e retomado em 2019. Disponível em: https://www.youtube.com/watch?v=6b4su4CJWG8. Acesso em: 19 set. 2020

viii Referência brasileira para o saxofone clássico - pioneiro na utilização da técnica de respiração

circular nesta obra entre as gravações disponibilizadas no Youtube.

ix Disponível em: https://www.carlosgontijo.com.br/. Acesso em: 10 set. 2020
} 
Respiração circular e sua aplicabilidade ao discurso musical do II movimento... José de Carvalho Oliveira

parte dos intérpretes, talvez influenciados por Marcel Mule, tem-se guiado pela proposta composicional contida especificamente na partitura, procurando interpretar da forma mais fiel possível, ou seja, exatamente como está escrito. Sobre esse modelo de interpretação, de fidelidade total à partitura, um elemento nos chamou atenção no que se refere às estruturas fraseológicas, auditivamente - a sensação de quebra do fluxo fraseológico pelas pausas, o que também pode ser observado visualmente na partitura da obra, conforme demonstra a Figura 1.

Fig. 1: Improvisation et Caprice (1944) - Caprice, II movimento (c. 5-12).

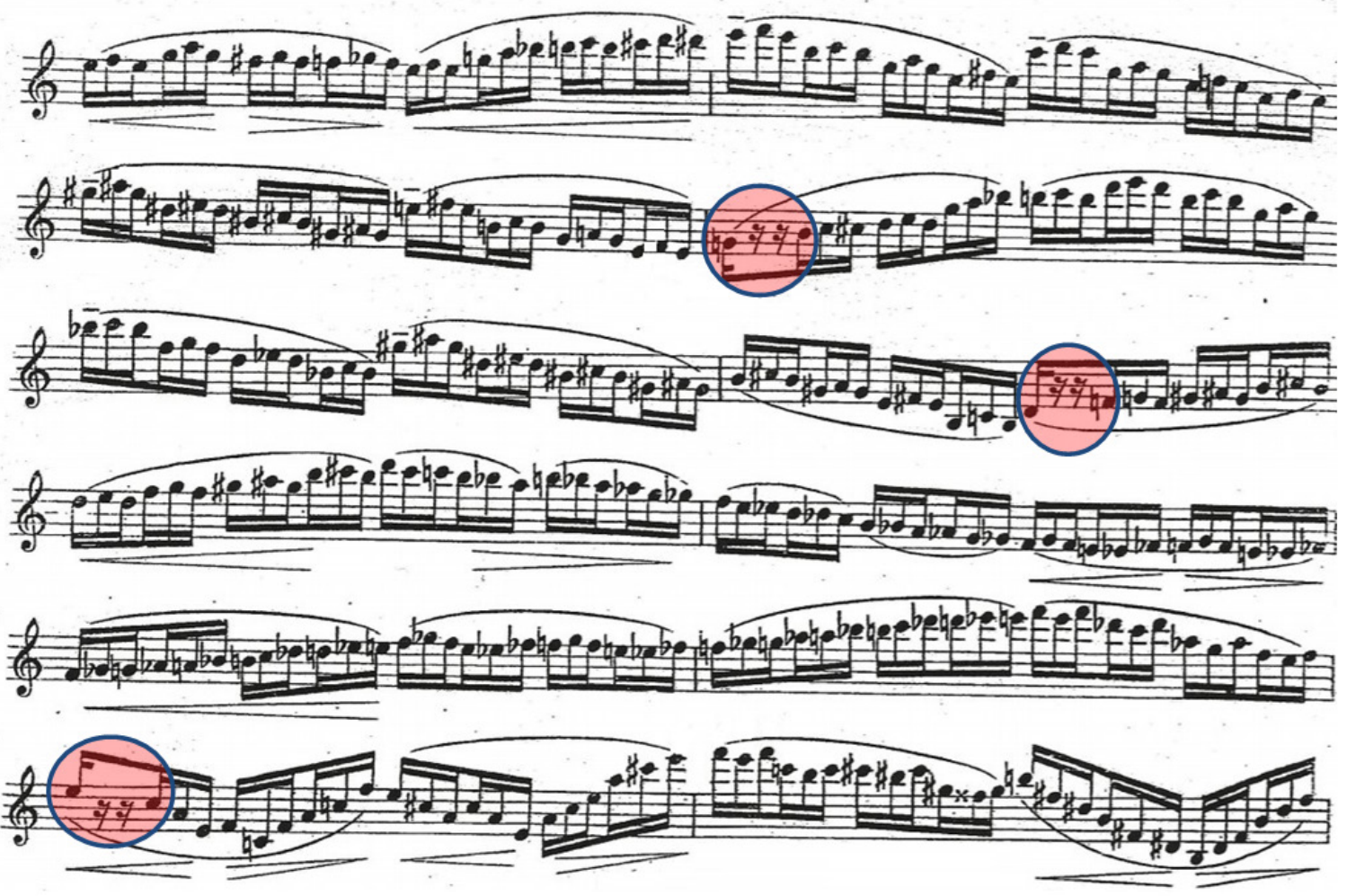

Fonte: Alphonse Leduc, 1952.

Em decorrência dessa observação, considerando que a obra é para instrumento de sopro e que a respiração do instrumentista ao longo desse movimento ocorre respectivamente nos tempos de pausa, emergem alguns questionamentos: 
Respiração circular e sua aplicabilidade ao discurso musical do II movimento... José de Carvalho Oliveira

1 - Se as pausas interrompem o fluxo musical demarcado pelas ligaduras de frase, qual a lógica composicional para que Bozza instituísse as pausas de maneira a soar como se as frases fossem interrompidas? 2 - Seria essa a razão das pausas? 3 - Como saber? 4 - As pausas teriam apenas a função de lugar para respirar, visto que o instrumentista de sopro necessita da respiração como ar combustível? 5 - Ou seriam as duas coisas? 6 - O compositor teria escrito a obra na intenção de uma interpretação em forma contínua em alusão ao Moto Perpétuo de Paganini (1830), porém substituiu as notas por pausas para facilitar a interpretação, considerando que a respiração circular é uma técnica estendida e que, talvez Marcel Mule, a quem a obra foi dedicada, não possuísse total domínio dessa técnica?

\section{Capriche VII de Eugène Bozza (1944) e Moto Perpétuo de Paganini (1830) - uma relação de paralelismo?}

Do ponto de vista fraseológico, diante dos questionamentos citados, em busca de uma melhor compreensão sobre os objetivos do compositor em relação à utilização das pausas em lugares não usuais, a partir de uma breve análise e contextualização do Caprice VII de Bozza (1944), apresentaremos alguns apontamentos que, em parte, dão sentido à função das pausas na obra.

Em 1944, a editora francesa Alphonse Leduc publicou um compêndio com 12 estudos para saxofone, escritos por Eugène Bozza (1905-1991). Em 1952, a mesma editora publicou uma edição com o sexto e o sétimo estudo do referido compêndio, combinando-os em um solo para saxofone, sem acompanhamento em dois movimentos. O primeiro, Improvisation, possui andamento lento, soando quase como uma improvisação clássica; já o segundo movimento, denominado Caprice, um aglomerado sucessivo de sextinas em andamento rápido, com apenas trinta compassos e com tempo de duração, em média, de um minuto e quinze segundos. 
Respiração circular e sua aplicabilidade ao discurso musical do II movimento... José de Carvalho Oliveira

De acordo com as descrições no prefácio dos Douze ÉtudesCaprices Pour Saxophone (1944) e na partitura da Improvisation et Caprice pour saxophone solo, editadas pela Alphonse Leduc (1952), tanto os estudos quanto a peça são dedicados ao lendário saxofonista clássico, o francês Marcel Mule, que, na ocasião, era professor de saxofone no Conservatório Nacional Superior de Música de Paris. Mule atuou nesta instituição de 1942 a 1968.

Acerca dos questionamentos levantados por esta pesquisa no que diz respeito ao suposto paralelismo com o Moto Perpétuo de Paganini, pela forma como Mule se expressa no prefácio dos Douze Études-Caprices Pour Saxophone (1944), é possível imaginar a viabilidade de Bozza ter escrito o segundo movimento (Caprice $V I I)$, realmente, com a intenção de moto perpétuo. "Com a imensa qualidade que está presente nestes estudos, eles estão para o saxofone como os Caprichos de Paganini para o violino, colocando, assim, o saxofone no mesmo nível de outros instrumentos solistas" (MULE, 1944, p. 1, tradução nossa).

Considerando as semelhanças entre o Caprice e Moto Perpétuo de Paganini (1830), em relação ao fluxo das frases e aos desafios intrínsecos, do ponto de vista técnico para o instrumentista, o comentário de Mule (1944) parece ganhar mais sentido ao olharmos os compassos finais da partitura do Moto Perpétuo de Paganini e compará-los aos compassos finais do Caprice.

Os elementos presentes no último compasso do Caprice, na versão ainda não editada como peça solo (1944), fortalecem o pensamento de que Bozza teria mesmo se espelhado na obra de Paganini. A relação se estabelece por intermédio de componentes análogos, desde as escalas com extensão de duas oitavas em movimento contrário, antecedendo uma espécie de gran finale, como também as pausas que, apesar dos valores não serem de igual proporção, ocupam a mesma espacialidade na representação do silêncio em ambas as obras. Somam-se a esses elementos os arpejos com o mesmo desenho rítmico e, também, a última nota da peça, uma terminação em fermata por intermédio de uma figura rítmica representada por uma semínima, conforme pode ser observado na Figura 2. 
Respiração circular e sua aplicabilidade ao discurso musical do II movimento... José de Carvalho Oliveira

Fig. 2: Elementos análogos nos compassos finais do Caprice VII, de Eugène Bozza (1944) e Moto Perpétuo N.11 de Paganini (1830).

Caprice VII - Eugène Bozza (1944)

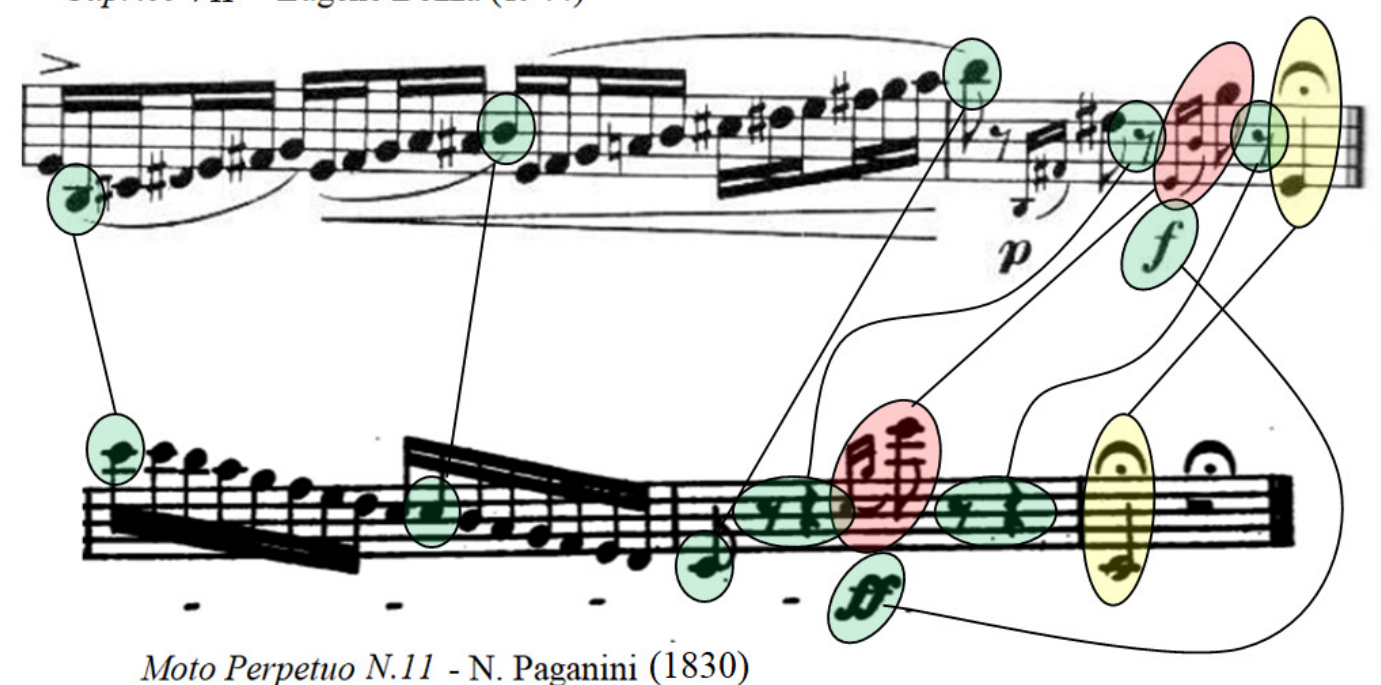

Fonte: Editoração do autor

Em corroboração ao pensamento acerca de uma possível influência de Paganini sobre o Caprice de Bozza e outras obras congêneres, sobretudo no tocante à quantidade de notas e ao uso da respiração circular, Steve Mauk (1994) compara o segundo movimento da Improvisation et Caprice com o Voo do Besouro, de Korsakov (1899-1900), sugerindo, inclusive, que a peça seja utilizada como referência:

(Sobre o segundo movimento, Caprice de Bozza). [...] Outra e única opção praticada por vários dos meus alunos é tocar a peça usando respiração circular, sem um descanso sonoro. Obviamente, o músico deve ter domínio dessa técnica e deve recompor as notas faltantes. O efeito pode ser impressionante quando bem feito. Minha sugestão final diz respeito a estilo e imagens mentais. O efeito geral do Caprice de Bozza é bastante semeIhante ao The Flight the Bumble Bee de Rimsk-Korsakov. Sugiro que o saxofonista imagine uma abelha, com seu zumbido ficando cada vez mais alto e suave como é o zumbido, e tente imitar esse som nas mudanças de dinâmicas da peça. (MAUK, 1994, p. 56, grifo nosso, tradução nossa). 
Respiração circular e sua aplicabilidade ao discurso musical do II movimento... José de Carvalho Oliveira

Com relação à contextualização dos Douze Études-Caprices Pour Saxophone (1944), vale ressaltar que, em meados do século $X X$, surgiram novas correntes musicais conduzindo os instrumentistas a buscarem novas sonoridades por intermédio também das técnicas estendidas, conforme comenta Costa et al. (2013):

(Sobre a busca por novas sonoridades e experimentalismos) [...] Remonta às práticas do experimentalismo da segunda metade do século XX numa clara referência às formulações de Karlheinz Stockhausen, John Cage, Vinko Globokar, Terry Riley e La Monte Young, e à rica história do Jazz que desemboca, aproximadamente na mesma época, no Free Jazz por meio da atuação de músicos como John Coltrane, Cecil Taylor, Ornette Coleman e Eric Dolphy. (COSTA et al., 2013, p. 2).

A busca por novas possibilidades sonoras contemplou também o retorno ao virtuosismo neoclássico, influenciando o fomento de obras como os Doze Estudos de Bozza para saxofone, estimulando instrumentistas a explorar novas experiências e execuções de obras desafiadoras aos instrumentistas de sopro, como, por exemplo, Flight the Bumble Bee de Rimsk-Korsakov (1899-1900), ${ }^{\mathrm{e}} \mathrm{e}$ Moto Perpétuo Op. 11,vi de Paganini (1830).

A interpretação de obras, como as citadas acima, por um instrumento de sopro requer, como condição sine qua non, a utilização da respiração circular ou contínua, reputada atualmente até com certa naturalidade, em decorrência do desenvolvimento das técnicas instrumentais em comparação à segunda metade do século XX, conforme comenta Barbosa (2016):

(Sobre respiração circular). [...] Esta técnica pode ser utilizada em qualquer estilo de música como, por exemplo, em música tradicional quando algumas frases são quebradas devido a problemas de respiração. Outro exemplo são as transcrições do repertório de cordas para clarinete. Os instrumentistas de cordas não necessitam de respirar, logo nós clarinetistas temos que usar uma alternativa, como a respiração circular, devido às frases longas que não nos permitem respirar. (BARBOSA, 2016, p. 22). 
Respiração circular e sua aplicabilidade ao discurso musical do II movimento... José de Carvalho Oliveira

\title{
3. A respiração circular
}

Quanto à ação denominada respiração circular, salientamos que se trata de uma técnica que consiste em realizar os tempos de inspiração e expiração ininterruptamente, ou seja, não se utilizando dos intervalos de espaço cheio e vazio. tornando a respiração um movimento circular e, assim, provocando a hiperventilação ou hiperoxigenação do corpo, comumente chamada por músicos de sopro de respiração circular ou respiração contínua.

Essa técnica também pode ser utilizada para fins terapêuticos (LOPES, 2018), como, por exemplo, no processo de equilíbrio da energia do corpo apenas com o fluxo de respiração, sem a necessidade de utilizar-se da mente. Sobre esse tipo de utilização, Lopes (2018) descreve, junto com a música, como sendo as terapias mais antigas da humanidade:

\begin{abstract}
A música e a respiração circular são consideradas uma das mais antigas terapias do mundo. A técnica foi usada no xamanismo como uma forma de cura para algumas doenças. O xamanismo foi espalhado para outras partes do mundo pelos colonistas europeus nos séculos XVI e XVII. Os xamãs acreditam que os exercícios de respiração, juntamente com o decorrer de uma música constante, conseguiam tratar algumas doenças dos pacientes. (LOPES, 2018, p. 43).
\end{abstract}

Sobre a utilização da respiração circular por instrumentistas de sopro, a técnica possibilita a produção de som contínuo sem a necessidade de quebrar uma linha musical. Em composições contemporâneas, a respiração circular está bastante associada a um meio de expressão e não apenas como uma técnica simplesmente física que permite que o músico toque por longos períodos de tempo. No entanto, no que se refere à sua origem, existem poucas informações na literatura geral sobre o assunto, dando margem 
Respiração circular e sua aplicabilidade ao discurso musical do II movimento... José de Carvalho Oliveira

a hipóteses de que essa técnica tenha se desenvolvido ainda no início da Era Cristã, quando os sírios inventaram a técnica do vidro soprado, revolucionando toda a atividade vidreira.

Acerca da aplicabilidade da técnica pelos instrumentistas de sopro, segundo Lopes (2018, p. 44-45), a respiração circular era usada principalmente para retratar os aspectos sociais e culturais da música tradicional dos povos antigos, bastante comum na música das culturas aborígenes australianas. À medida que essa música tradicional começou a ser ouvida além dos seus países de origem, a respiração circular começou a expandir-se para os países da Europa Ocidental. Atualmente, a respiração circular é relativamente conhecida por boa parte dos instrumentistas de sopro, sendo, talvez, muito mais explorada na música ocidental que outrora, sobretudo na música contemporânea que, apesar do esforço por parte de alguns docentes ao incorporá-la às práticas pedagógicas no ensino dos instrumentos de sopro, ainda permanece no hall das chamadas técnicas estendidas.

\section{Caprice - Estrutura; Movimento Cadencial; Articulação da Forma e Notas ocultadas}

\subsection{Análise Estrutural}

De cunho virtuosístico, ritmo estável, com apenas 30 compassos e andamento em torno de 100 batidas por minutos (bpm), o movimento denominado Caprice estrutura-se sobre a tonalidade de Mi menor. Em relação ao material harmônico, motívico e temático, além da utilização de cromatismo, destaca-se o emprego de quiálteras de seis (sextinas).

Levando em consideração a maneira como está organizado o material motívico, melódico, harmônico e temático, além da estrutura cadencial das frases, esse movimento pode ser dividido em três seções, sendo: parte A, B e A', conforme demonstra o Quadro 1. 
Respiração circular e sua aplicabilidade ao discurso musical do II movimento... José de Carvalho Oliveira

\section{Quadro 1: Características formais e estrutura composicional}

\begin{tabular}{|c|c|c|}
\hline \multicolumn{3}{|c|}{$\begin{array}{c}\text { Improvisation et Caprice, Eugène Bozza (1944) } \\
\text { II movimento, Caprice (c.1-30) }\end{array}$} \\
\hline \multicolumn{2}{|c|}{ FORMA } & $A-B-A^{\prime}$ \\
\hline Compasso & Seção & Material Temático \\
\hline $1-14$ & A & $\begin{array}{l}\text { Esta seção está estruturada sobre o centro sonoro de Mi menor, } \\
\text { se caracterizando pelo motivo rítmico e melódico em quiálteras } \\
\text { de sextinas em figuras de semicolcheias. Com fórmula de com- } \\
\text { passo quaternária, possui melodia angulosa que se desenvol- } \\
\text { ve por grau conjunto sem perder a referência das quiálteras de } \\
\text { seis. Concernente ao material harmônico, notabiliza-se a pre- } \\
\text { dominância do uso de cromatismo com apenas alguns poucos } \\
\text { saltos de } 3^{a}, 4^{a} \text { e } 5^{a} \text {. }\end{array}$ \\
\hline $15-26$ & B & $\begin{array}{l}\text { Seção caracterizada pela alternância de fórmulas de compasso } \\
\text { entre quaternária, ternária e binária. Notabiliza-se também pelo } \\
\text { desenvolvimento do motivo rítmico e melódico em formato de } \\
\text { arpejos e saltos de } 8^{\mathrm{a}}, 10^{\mathrm{a}} \text { e } 11^{\mathrm{a}} \text {, além da mudança de direciona- } \\
\text { mento das frases, atingindo o ápice no que se refere à angulosi- } \\
\text { dade da melodia entre o Si } 2 \text { e Fá } 5 \text { (sons escritos). }\end{array}$ \\
\hline $27-30$ & $A^{\prime}$ & $\begin{array}{l}\text { Reapresentação do tema principal por intermédio do motivo } \\
\text { rítmico e melódico inicial em quiálteras de seis. Caracteriza-se } \\
\text { também pelo uso das escalas de Si Maior, Mí bachiana (c.28) e } \\
\text { arpejo de Mi menor com finalização sobre a fundamental. }\end{array}$ \\
\hline
\end{tabular}

Fonte: Elaborado pelo autor.

Quanto à articulação da forma e a maneira como se conectam as partes dentro de uma estrutura, geralmente, essa delimitação ocorre pelo uso de cadências, ou simplesmente por metas harmônicas, conforme se refere Kostka (2015, p. 133), ressaltando que "mesmo uma peça que nunca diminui seu movimento (um "moto perpétuo") conterá cadências". De fato, o que encontramos neste segundo movimento, denominado Caprice, é uma espécie de ponto de chegada ou "meta harmônica", cujo surgimento, de acordo com Kostka (2015), nem sempre estará atrelado a uma cadência entre os tipos "padrão" da música tonal, "às vezes seu surgimento pode não formar qualquer padrão" (KOSTKA, 2015, p. 133). Dessa maneira, observa-se que a seção A (c. 14) termina com uma espécie de cadência dual que acontece quase simultaneamente entre os acordes de Ré bemol maior resolvendo em Lá menor e Dó maior resolvendo em Fá maior, conforme se observa na Figura 3. 
Respiração circular e sua aplicabilidade ao discurso musical do II movimento... José de Carvalho Oliveira

Fig. 3: Movimento cadencial e articulação da forma entre o final da seção A (c.14) e início da seção B (c. 15). Caprice, Eugène Bozza, (1944).
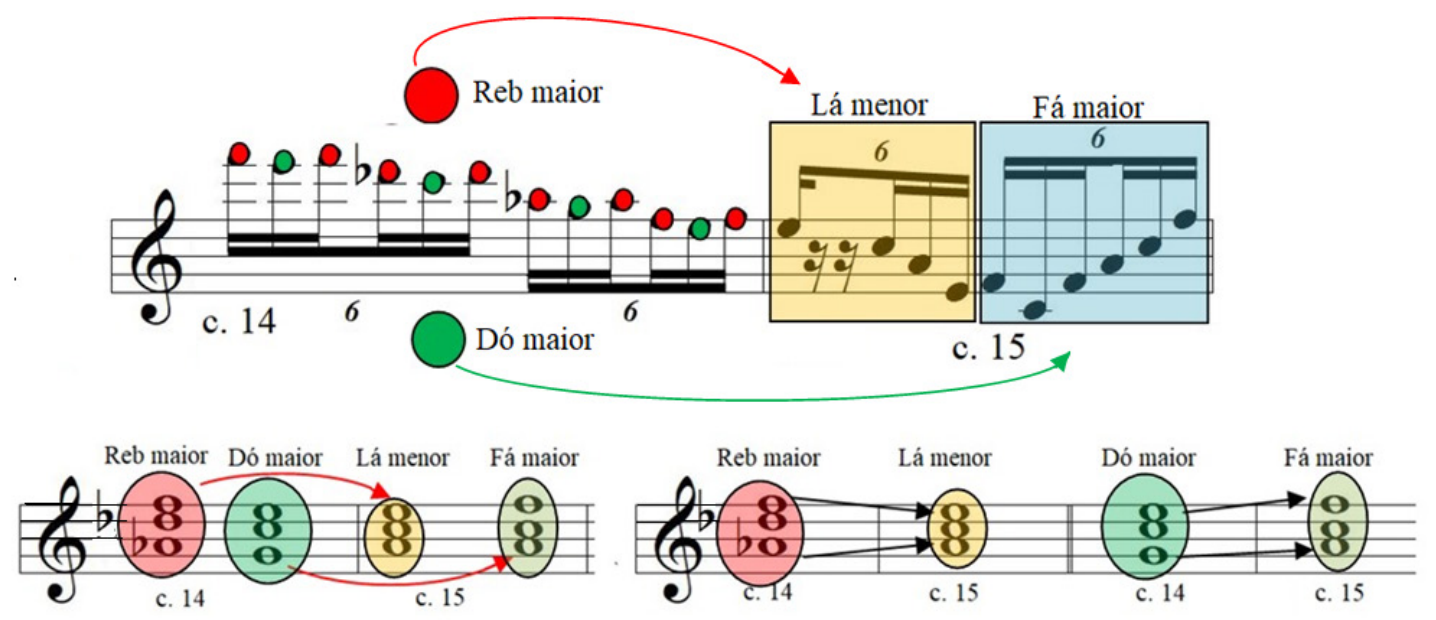

Fonte: Editoração do autor.

Nesse caso, embora Bozza não se utilize dos meios tradicionais para alcançar o que Kostka (2015) denomina como "meta harmônica", a resolução da tensão acontece na forma convencional, conforme demonstrado na figura acima.

Além do modelo de cadência observado (c.14 - 15), Bozza também faz uso de outras maneiras para articular a forma, onde as tensões são representadas por mudança de direcionamento de frases, mudança de fórmula de compasso, ampliação e diminuição da angulosidade da melodia. Notabiliza-se também o uso de escalas cromáticas que, quando utilizadas para fins cadenciais e de articulação da forma, encontram repouso e estabilidade na nota de chegada (c. 4 e 26).

Concernente à manipulação do material temático, o centro sonoro em Mi menor é evidenciado, sobretudo, na seção A, apesar do uso de alguns acordes que não possuem relação tonal entre si, como, por exemplo, Sol\# maior (c. 7 e 9), Si bemol maior (c.9), Mi maior (c.10) e Sol\# diminuto (c.10 -11).

O motivo que origina todo o desenvolvimento temático ao longo desse movimento inicia-se com a nota Mi, desdobrando-se 
Respiração circular e sua aplicabilidade ao discurso musical do II movimento... José de Carvalho Oliveira

em variações cromáticas e, às vezes, arpejada até a retomada da temática inicial na seção A' (c. 27-30). Nesta seção (A'), Bozza reapresenta o tema principal utilizando arpejos de Mi menor e finalizando a peça na tônica dessa tonalidade. Sobre o movimento cadencial entre os compassos 28-29, o tensionamento acontece por intermédio da escala de Si Maior com sexta menor e a escala bachiana de Mi.

\subsection{Busca pelas notas ocultas}

Em uma tentativa de evidenciar as supostas notas musicais que melhor se encaixam na estrutura da frase em substituição das pausas, utilizamos como parâmetro de coerência a análise fraseológica da construção melódica e harmônica, levando em consideração a delimitação das frases balizadas pelas ligaduras.

Em relação às pausas, elas aparecem em cinco momentos do discurso musical, respectivamente nos compassos 4, 8, 10, 15 e 23. Na primeira aparição (c.4), ao analisarmos o caminho melódico e harmônico, verificamos tratar-se de uma reapresentação do motivo rítmico e melódico apresentados na abertura da peça (c. 1). No entanto, nessa reapresentação, a segunda nota e a terceira (Fá e Mi) foram substituídas por figuras de pausas, conforme se observa na Figura 4.

Fig. 4: Caprice (1944) - II movimento (c. 1-4). Substituição de notas por pausas na reapresentação do motivo rítmico e melódico.

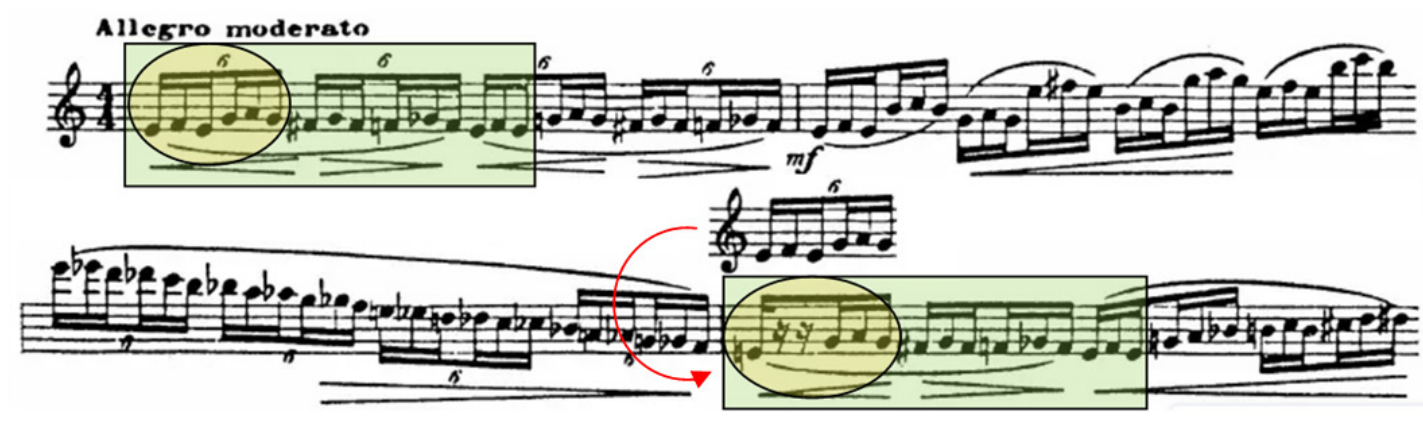

Fonte: Edição Alphonse Leduc, 1952. 
Respiração circular e sua aplicabilidade ao discurso musical do II movimento... José de Carvalho Oliveira

Na segunda vez que as pausas aparecem (c.8), levando em consideração a construção do motivo rítmico e melódico estruturado a partir de uma quiáltera de seis, subdividida em duas quiálteras de três, tendo em vista a organização melódica por grau conjunto, observa-se que, para cada três semicolcheias, a segunda semicolcheia aparece sempre como uma espécie de bordadura superior. A partir dessa observação, é possível imaginar que as duas notas ocultadas ou que melhor se encaixam no caminho harmônico e melódico em substituição às pausas nesse compasso seriam as notas Lá e Sol. O mesmo procedimento utilizado neste compasso (c.8) refere-se também aos próximos três lugares onde aparecem outras pausas, conforme pode ser observado nas Figuras 5, 6, 7 e 8 .

Fig. 5: Caprice (c.7-8). Indicação das possíveis notas ocultadas para dar lugar às pausas para respiração.

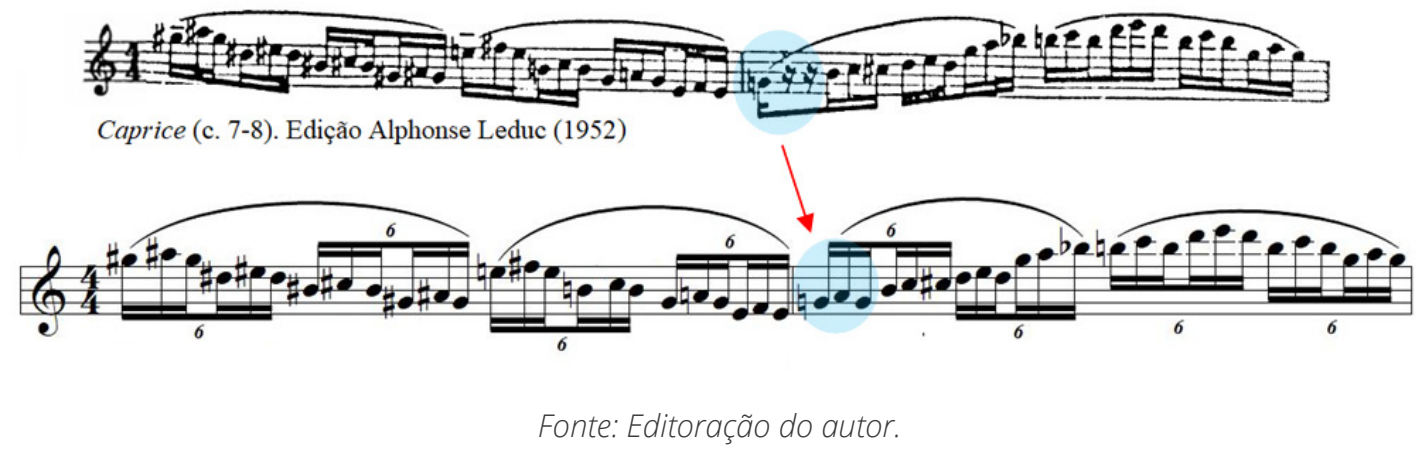

Fig. 6: Caprice (c.10). Indicação das possíveis notas ocultadas para dar lugar às pausas para respiração.

Caprice (c.10). Edição Alphonse Leduc (1952)

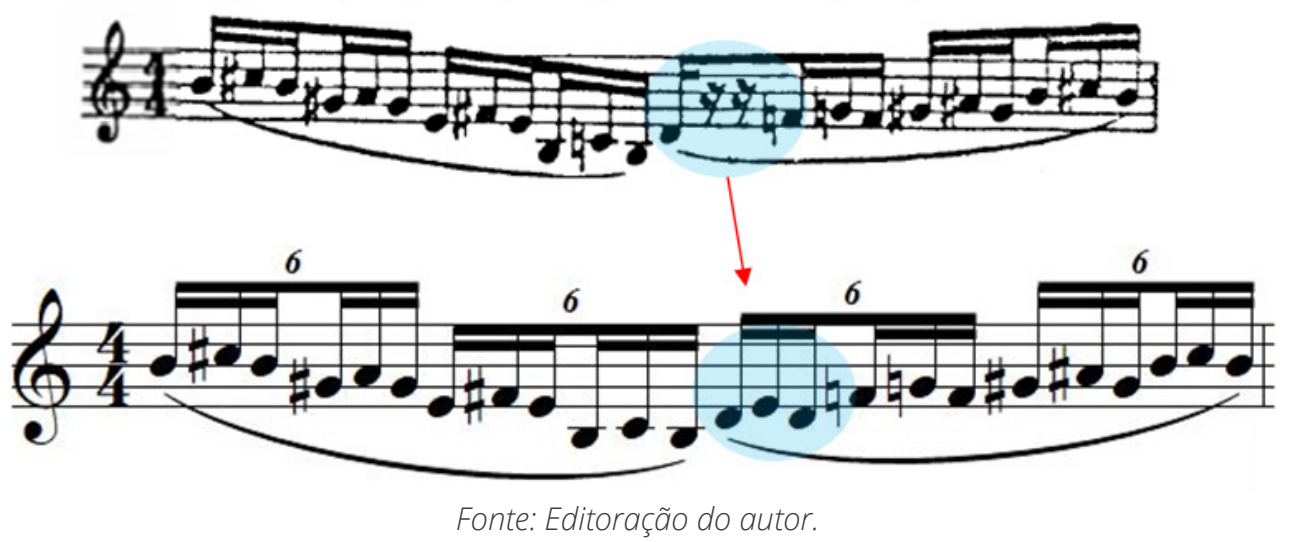


Respiração circular e sua aplicabilidade ao discurso musical do II movimento... José de Carvalho Oliveira

Fig. 7: Caprice (c.15). Indicação das possíveis notas ocultadas para dar lugar às pausas para respiração.

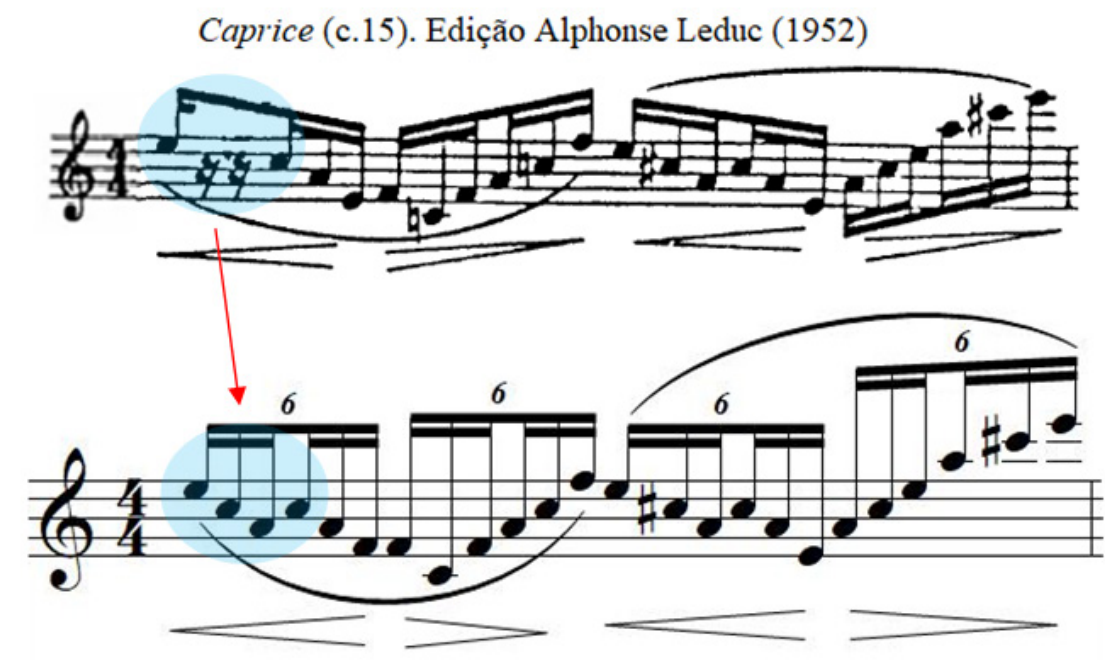

Fonte: Editoração do autor.

Fig. 8: Caprice (c.23). Indicação da possível nota ocultada para dar lugar à pausa para respiração Caprice (c.23). Edição Alphonse Leduc (1952)

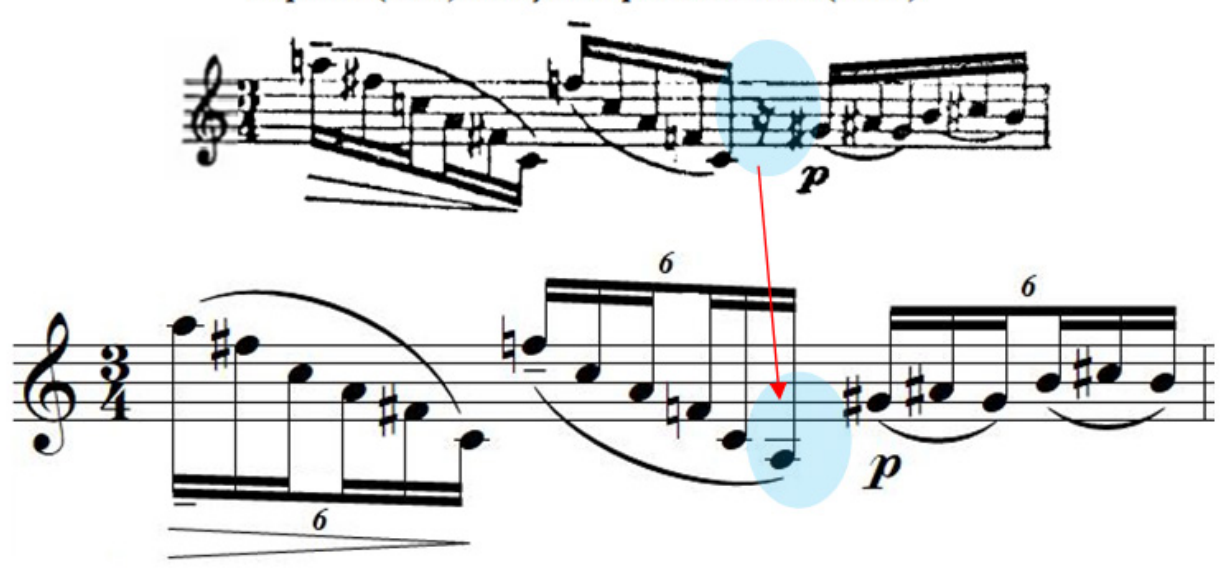

Fonte: Editoração do autor.

Sobre a substituição da pausa por uma figura de som (Figura 8), a construção melódica e harmônica da referida frase aponta a nota Lá 2 como a mais coerente para ocupar esse espaço, por se tratar do arpejo de Fá maior descendente. No entanto, a tessitura do saxofone não alcança essa nota, dado que a extensão do instrumento se limita entre Si bemol 2 e Fá sustenido 5 (sax 
Respiração circular e sua aplicabilidade ao discurso musical do II movimento... José de Carvalho Oliveira

soprano, alto e tenor - sons escritos). Apenas o saxofone barítono situa-se entre o Lá 2 e Fá sustenido 5 (sons escritos), entretanto, não é usual a utilização do barítono nesta peça. A partir dessas observações e pensando em uma interpretação em moto perpétuo, conforme sugestão da proposta, para colocar em prática seria necessário fazer uma alteração da nota Lá 2, reescrevendo-a uma oitava acima (Lá 3) ou prolongando a nota que a antecede, preenchendo o tempo da pausa com a nota Dó 3, abdicando-se do Lá.

Entre as duas opções, apresenta-se como a mais exequível e funcional a segunda delas, o prolongamento da nota Dó 3, visto que a opção anterior, teoricamente, apesar de funcional, do ponto de vista técnico e prático, uma troca de registro entre duas notas em intervalo de sexta maior na região extremo grave do instrumento (Dó3 - Lá3) exigiria muito mais do intérprete em consequência do andamento rápido ao qual a peça está submetida.

Referente à movimentação horizontal das vozes condutoras, estrutura e prolongação, com base nos estudos de Salzer (1982), na busca por fluência dentro do discurso musical, um dos fatores importantes para o entendimento da peça, como um todo, foi a redução da partitura a partir do empilhamento de notas transformando a melodia em acordes, conforme demonstrado na Figura 9.

Fig. 9: Improvisation et Caprice, Eugène Bozza (1944). II mov. (c. 1-30). Empilhamento de notas / verticalização da melodia. Os números em vermelho representam os locais onde originalmente se encontram as pausas.
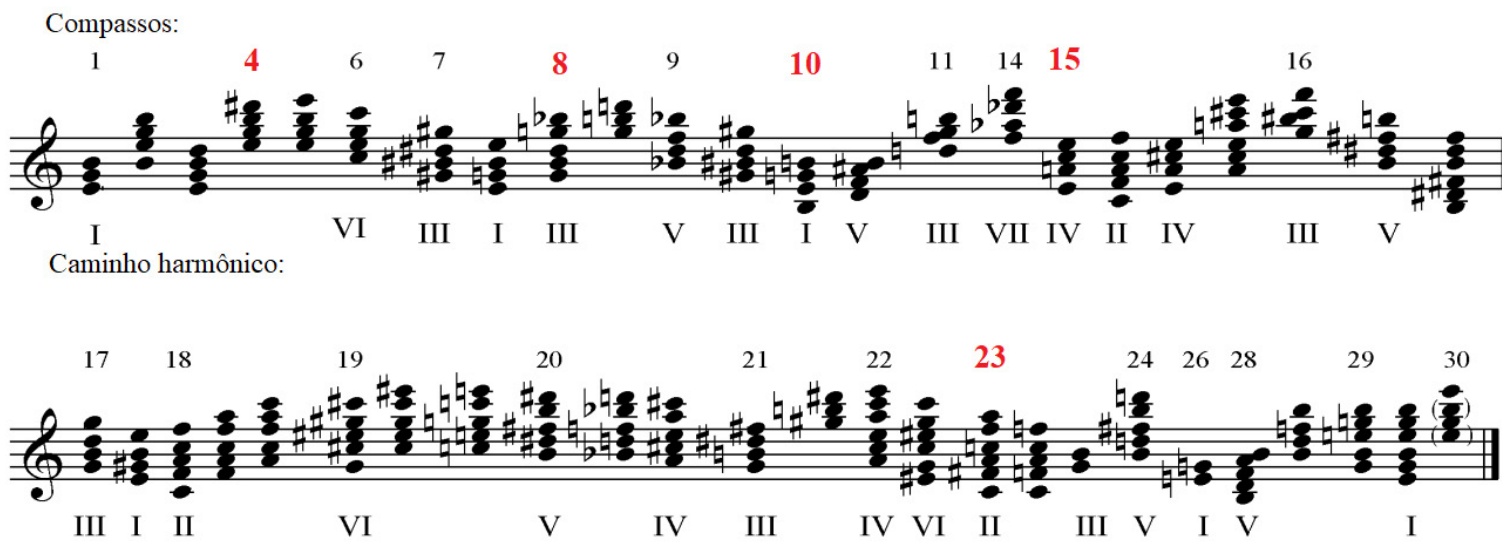

Fonte: Editoração do autor. 
Respiração circular e sua aplicabilidade ao discurso musical do II movimento... José de Carvalho Oliveira

A figura acima nos permite visualizar o movimento da textura e a melodia explicitada nos acordes, além de nos servir de base para chegarmos ao próximo gráfico, demonstrado na Figura 10.

Fig. 10: Gráfico das vozes condutoras. Estrutura, prolongação e organicidade. Eugène Bozza, Improvisation et Caprice (1944), II mov. Caprice (c. 1-30).

Improvisation et Caprice, Eugène Bozza (1944). II mov. (c. 1- 30).
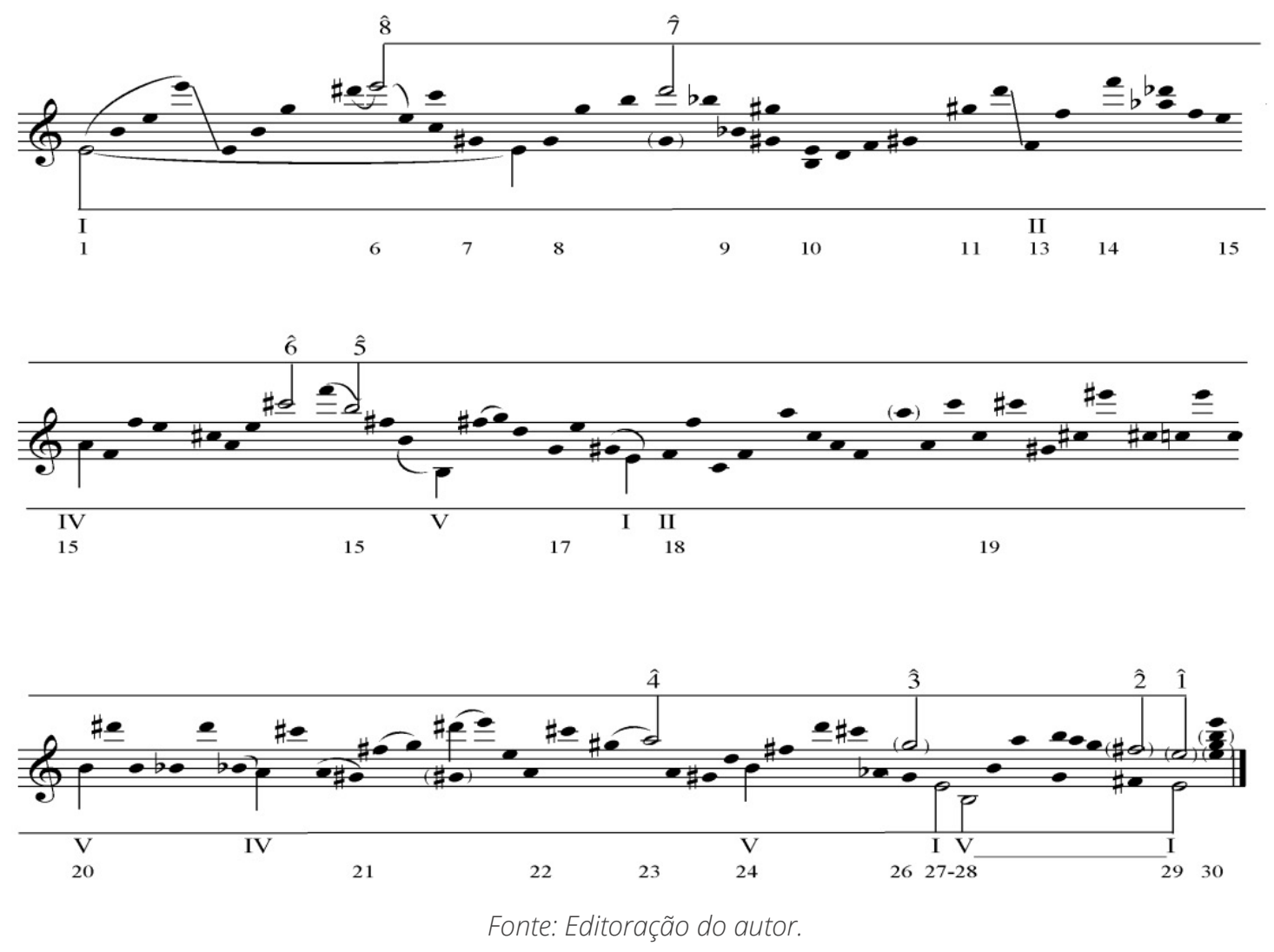

No gráfico apresentado acima, foram interpretadas como metas provisórias (meta harmônica) as notas pretas com haste. A movimentação entre as metas provisórias é compreendida por este estudo como prolongamento de acorde. As notas brancas, com hastes ligadas por uma barra na parte superior e enumeradas por $8,7,6,5,4,3,2,1$, chamada de linha fundamental, segundo Salzer (1982), são as notas estruturais da superfície da peça; os números colocados acima de cada uma destas notas representam o grau correspondente à tonalidade em questão (Mi menor). A estrutura 
Respiração circular e sua aplicabilidade ao discurso musical do II movimento... José de Carvalho Oliveira

do plano fundamental na voz inferior (região médio grave do instrumento) é representada pelas mínimas ligadas pela barra, referindo-se aos graus I-V-I.

\section{Estudo interpretativo e preparação à performance}

O processo de estudo e preparação à performance do segundo movimento da obra Improvisation et Caprice, objetivo central deste estudo, possui como proposta interpretativa a execução deste movimento em moto perpétuo a partir da substituição das pausas pelas notas supostamente ocultas ou as que melhor se encaixam, conforme levantamento demonstrado na análise musical.

Para alcançar esse objetivo, este estudo buscou avaliar, a partir da escolha interpretativa, o sentido de continuidade das frases a começar pela substituição das pausas por figuras de som. Para tanto, levaram-se em consideração todas as indicações presentes na partitura, exceto as pausas, desde o mais básico, como fórmula de compasso, a questões contextuais externas à partitura.

Com relação à preparação e construção da performance, objetivou-se integralizar elementos importantes para a materialização do enunciado poético em um processo dinâmico, procurando contemplar, de forma igualitária, seus diversos agentes e até as mais subjetivas questões, dividindo-se em três partes da seguinte forma:

- Primeira - estudo técnico envolvendo andamento, ritmo, afinação, fluência do fraseado e conexão das partes no que diz respeito à forma e material temático.

- Segunda - interpretação: junção da técnica com a poética tendo como objetivo a fluência técnico-interpretativo, relacionando agilidade do dedilhado ao discurso musical, dinâmicas e construção das frases balizadas pelo caminho 
Respiração circular e sua aplicabilidade ao discurso musical do II movimento... José de Carvalho Oliveira

melódico, ligaduras e questões harmônicas, concentrando-se maiormente no estudo e prática da respiração circular. No entanto, essa etapa limitou-se apenas a questões de sua aplicabilidade ao discurso musical, visto que um maior aprofundamento no que se refere a demandas pedagógicas extrapolaria o escopo deste artigo. Devido a isso, nos atemos ao estudo técnico e interpretativo, porém com o emprego da respiração circular como ferramenta de conexão entre as frases, buscando-se resistência na troca do ar, fluidez no discurso e equilíbrio sonoro a partir da substituição das pausas por notas musicais, conforme visto nas Figuras 5-8.

- Terceira - preparação à performance: execução da peça em forma de simulação de um recital com o objetivo de proporcionar o momento instantâneo e efêmero de enunciação da obra (processo que só ocorre durante a performance), direcionado em algum grau pela concepção interpretativa, mas repleto de imprevisíveis variáveis (ALMEIDA, 2011).

Acerca dos aspectos de resistência física, como parte da rotina diária durante a pesquisa e como plataforma de estudo da respiração circular, utilizamos a prática das escalas maiores em tonalidades variadas e em toda extensão do instrumento, repetindo ininterruptamente por várias vezes cada escala (looping), conforme demonstra a Figura 9.

Fig. 9: Escala de Si Maior em toda extensão do saxofone. Exemplo de modelo de escala estudada em forma de looping para aplicação da respiração circular.

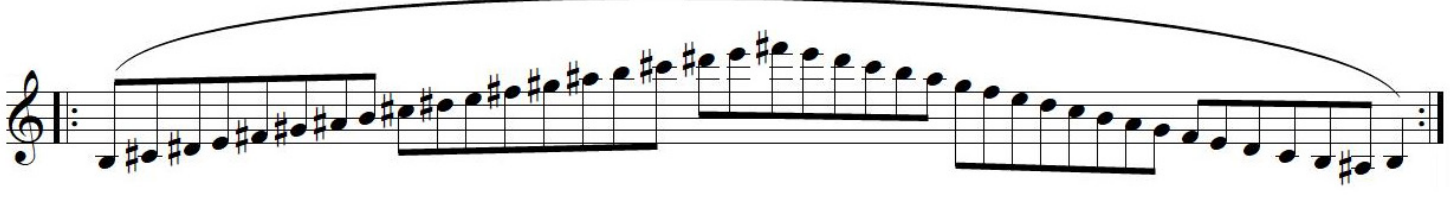

Fonte: Editoração do autor. 
Respiração circular e sua aplicabilidade ao discurso musical do II movimento... José de Carvalho Oliveira

Sobre a preparação para a performance, terceira parte deste estudo, destacamos os resultados referente à preparação e, também, à performance propriamente dita, realizada em um recital na cidade de Embu das Artes - SP, no ano de 2013. viii

Os apontamentos apresentados a seguir dizem respeito aos benefícios e desafios em relação a questões que ainda necessitam de maior aprofundamento sobre o uso da respiração circular:

- Aspectos positivos em relação ao uso da respiração circular: Ampliação da capacidade respiratória e maior controle sobre o sistema respiratório. Oferece sentido de continuidade ao fluxo sonoro a partir da respiração circular. A interpretação e a performance com respiração circular, como proposto por este estudo, aproxima a Improvisation et Caprice a obras com características análogas (MULE, 1944, p. 1).

- Aspectos positivos em relação à performance: Com o uso da respiração circular, se bem executada, o efeito é impressionante (MAUK, 1994, p. 56), não apenas do ponto de vista de outros intérpretes, mas, sobretudo, da plateia em geral, fato que nos leva a acreditar que talvez tivesse sido realmente essa a principal intenção de Eugène Bozza.

- Desafios: A interpretação deste movimento (Caprice), por si só, já se configura em um grande desafio técnico. Ao optar pela respiração circular, faz-se necessário que o intérprete possua, no mínimo, domínio satisfatório do texto musical, pois, a partir desse pressuposto, acrescentar-se-ão as notas musicais no lugar das pausas, iniciando uma nova fase do estudo. Esta etapa consistirá em uma busca pela resistência física e controle do discurso musical por intermédio da repetição. O controle almejado não se restringe apenas às alturas das notas, mas também à articulação, ao timbre e à dinâmica temporal, buscando o máximo de fluidez no discurso musical. 
Respiração circular e sua aplicabilidade ao discurso musical do II movimento... José de Carvalho Oliveira

Referente à interpretação com respiração circular, talvez, pelo grande desafio técnico entre as inúmeras gravações da Improvisation et Caprice disponibilizadas na plataforma do Youtube, esta pesquisa apurou um número pequeno de performances que apresentam a interpretação com o uso da respiração circular de forma integral no segundo movimento. Entre as gravações encontradas por esta pesquisa até a finalização deste artigo, são respectivamente dos intérpretes: Dílson Florêncio, viii Carlos Gontijo, ix José de Carvalho e Colin Crake, conforme pode ser observado no Quadro 2.

Quadro 2: Lista de publicações e visualizações da Improvisation et Caprice pour saxophone solo. Performance do II movimento, Caprice - com respiração circular.

\begin{tabular}{|c|l|l|l|l|c||}
\hline \hline Intérprete & \multicolumn{1}{|c|}{ Link } & Views & Ano & UF & País \\
\hline $\begin{array}{c}\text { Dílson } \\
\text { Florêncio }\end{array}$ & $\begin{array}{l}\text { https://www.youtube.com/watch?v=C4clEds- } \\
\text { qty4 }\end{array}$ & 18.348 & 2009 & SC & Brasil \\
\hline $\begin{array}{c}\text { Carlos } \\
\text { Gontijo }\end{array}$ & $\begin{array}{l}\text { https://www.youtube.com/watch?v=IAmN62Y- } \\
\text { ZlBg }\end{array}$ & 872 & 2013 & BA & Brasil \\
\hline $\begin{array}{c}\text { José de } \\
\text { Carvalho }\end{array}$ & $\begin{array}{l}\text { https://www.youtube.com/watch?v=6b4su4C- } \\
\text { JWG8 }\end{array}$ & 4.451 & 2013 & SP & Brasil \\
\hline $\begin{array}{c}\text { Colin } \\
\text { Crake }\end{array}$ & $\begin{array}{l}\text { https://www.youtube.com/watch?v=OvacH- } \\
\text { qO9Q-A }\end{array}$ & 3.307 & 2017 & NY & USA \\
\hline \hline
\end{tabular}

Fonte: Elaborado pelo autor com base nos dados colhidos na plataforma digital do Youtube, em 19 set. 2020

\section{Considerações finais}

Sobre a tradição textual e seu vínculo à partitura enquanto documento fixador, este estudo abordou a importância de considerar que as práticas interpretativas contemporâneas contribuem para aproximar as interpretações atuais às obras do passado. No que se refere a esta questão, Almeida (2011) chama atenção para os perigos não somente do dogmatismo musical, mas da tendência em convergir todas as possibilidades interpretativas de uma obra 
Respiração circular e sua aplicabilidade ao discurso musical do II movimento... José de Carvalho Oliveira

para um único ponto, considerando-o musicalmente legítimo. “[...] É inegável que a abordagem de uma obra se aprofunda ao considerar não apenas o que nela há de texto fixo, mas também sua instabilidade que proporciona uma multiplicidade de resultantes interpretativas a partir de uma única partitura" (ALMEIDA, 2011, p. $66)$.

Acerca das expectativas propostas por este trabalho, há de se considerar a exposição de pontos importantes em relação aos processos interpretativos, oferecendo a reflexão de que, embora uma obra esteja dentro de parâmetros que a identifiquem como uma obra fechada, haverá sempre espaço para a colaboração do intérprete e que a manifestação musical considerada em seu dinamismo não é algo congelado em um suposto estado de pureza, fora do tempo e de suas contingências.

Com relação aos aspectos relatados, é importante considerar a necessidade de posturas investigativas no que se refere à musicologia voltada à música como performance, tendo em vista que o intérprete é "um terceiro ator, a quem - em se tratando de música instrumental/vocal - cabe apresentar e distender a obra linearmente no tempo, e cuja atividade agrega concretude sonora a estruturas abstratas" (ALMEIDA, 2011, p. 67).

Referente aos resultados da pesquisa sobre qual seria a meIhor interpretação ou a mais coerente segundo o enunciado e o texto musical - com respiração circular ou sem respiração circular, respeitando as pausas, apesar de auditivamente causar a sensação de quebra do fluxo musical (com as pausas) - os gráficos das vozes condutoras (Figuras 9 e 10) apontam que ambas as possibilidades não interferem no plano melódico e estrutural da obra.

Quanto à interpretação fazendo uso da respiração circular, dada a quantidade de notas tocadas em um movimento continuado, conforme visto na verticalização da melodia (Figura 9), evidenciam-se aspectos de uma melodia polifônica que trabalha em decorrência da harmonia, porém, auditivamente, não ficam tão 
Respiração circular e sua aplicabilidade ao discurso musical do II movimento... José de Carvalho Oliveira

claras ou ficam menos perceptíveis às cadências e às progressões harmônicas.

Já em relação à opção interpretativa, sem o uso da respiração circular, mas considerando as pausas, auditivamente, o caminho harmônico fica mais evidente, já que é reforçado pelas dinâmicas decrescentes nos finais de frase antes das respirações. Até mesmo em casos que efetivamente não ocorre uma cadência, o instrumentista, involuntariamente, compromete-se por fazer acabamentos nestas terminações e, o interessante, a simples parada para respirar induz o ouvido a entender esse momento como um movimento cadencial.

No que está relacionado ao paralelismo com o Moto Perpétuo de Paganini, dois fatores contribuíram significativamente para a inclinação de que Eugène Bozza tenha, de fato, composto o segundo movimento (Caprice) com a intenção de ser interpretado com respiração circular: as ligaduras de frase sempre começam antes das pausas (Figuras 4-8), o que sugere a possibilidade de 0 compositor ter escrito, inicialmente, sem as pausas e, em algum momento antes da edição final (1952), retirado algumas notas de lugares específicos, substituindo-as por pausas permitindo ao instrumentista respirar. Soma-se a isso considerar a possibilidade de colaboração de Marcel Mule quanto à escolha dos locais onde as notas foram substituídas por pausas, visto que são lugares estratégicos do ponto de vista fraseológico, harmônico e, sobretudo, para respiração do instrumentista. Sobre essa questão, Florêncio (2013) sugere que talvez o que tenha influenciado Bozza a colocar pausas no lugar de notas foi o fato de Marcel Mule não usar a técnica: "Marcel Mule não fazia respiração circular. Não existe nenhum registro dele fazendo uso dessa técnica. Como a peça foi escrita para ele, acredito que Bozza adaptou sua ideia ao intérprete" (OLIVEIRA, 2013). 
Respiração circular e sua aplicabilidade ao discurso musical do II movimento... José de Carvalho Oliveira

\section{Referências bibliográficas}

ALMEIDA, Alexandre Zamith. Por uma visão de música como performance. Opus, Porto Alegre, v. 17, n. 2, p. 63-76, dez. 2011.

BARBOSA, Tania Sofia Capela. Técnicas de respiração na aprendizagem do clarinete no nível básico do ensino especializado da música. 2016. 68 f. Dissertação (Mestrado em Música) - Instituto de Educação, Universidade do Minho, Braga, 2016.

BOZZA, Eugène. Douze Études - Caprices pour Saxophone. Paris: Alphone Leduc, 1944. Partitura.

BOZZA, Eugène. Improvisation et Caprice pour saxophone solo. Paris: Alphone Leduc, 1952. Partitura.

COSTA, R. L. M.; IAZZETTA, Fernando; VILLAVICÊNCIO, C. - Fundamentos técnicos e conceituais da livre improvisação. In: KELLER, D., QUARANTA, D.; SIGAL, R. (org.). Special Volume Sonic Ideas: Musical Creativity, Sonic Ideas, Morelia, v. 10, p. 49-55, 2013.

OLIVEIRA, José de Carvalho. Entrevista de Dílson Florêncio em 21 jul. 2013. São Paulo. Registro em e-mail. UFMG.

KOSTKA, Stefan; PAYNE, Dorothy. Harmonia Tonal. Traduzido a partir da Sexta edição, de 2008, por Hugo L. Ribeiro, Jamary Oliveira e Ricardo Bordini. Última atualização: 14 abr. 2015. Disponível em: http:// hugoribeiro.com.br/db-harmonia.php Acesso em: 22 dez. 2019.

LOPES, Claudio Roberto Fernandes. Respiração Circular. Método Pedagógico de Iniciação para Fagote. 2018. 130 f. Dissertação (Mestrado em Música) - Escola Superior de Artes Aplicadas, Instituto de Castelo Branco, Castelo Branco, 2018.

MAUK, Steve. Creative Teachin Techniques. Saxophone Journal, Ithaca, v. 19, n. 3, p. 54-56, 1994. Disponível em: https://openmusiclibrary.org/ article/643499/. Acesso em: 22 dez. 2019.

SALZER, Felix. Structural hearing: tonal coherence in music. New York: Dover Publications, Inc., 1982. 